\title{
César Vallejo: Premonición y Vísperas
}

Podria creerse, como sin duda se ha creído por la casi totalidad de los lectores de Vallejo, que los tan tepetidos versos

Me moriré en París con aguacero

un día del cual tengo ya el recuerdo $(189)^{1}$

traducen sencillamente un estado de angustia del poeta que con ese motivo se deja conducir por su tendencia a crear atmósferas psicológicamente irreales. El sujeto se nos presenta en situación intemporal por inversión de pasado y futuro, diríase, por el empleo más o menos consciente de un recurso literatio: "Me moriré... un día del cual tengo ya el recuerdo". Parecidamente había escrito en Trilce VI: "El traje que vestí mañana". (87)

Sin embargo, como se deben juzgar, esos versos no son un arbitrio estético para expresar un estado subjetivo, sino referencia a una no por extraña menos concreta premonición que el poeta había experimentado años atrás, una noche de 1920 en la casita de campo de su amigo An. tenor Orrego, en Mansiche, junto a Trujillo. Lo acreditan dos testimonios de primera mano que resulta interesante completar; porque ambos, un breve artículo del mismo Orrego y un capítulo de Espejo Asturrizaga -que no parece ser derivación del primero-, inducen a pensar que el suceso no fue de mera anécdota y sin más relieve que unos versos. Conviene demorarse en la escena central de las dos versiones:

Dormíamos ambos en el único dormitorio de la casa. Una noche me desperté sobresaltado a los gritos angustiados de mi huésped que me llamaba desde su lecho. Vallejo estaba delante de mí, temblando como azogado de la cabeza a los pies:

1 Los números entre paréntesis refieren a las páginas de la Editorial Losada: César Vallejo, Poesías Completas, Buenos Aires, 1949. Lamentamos no habet podido consultar la edición con facsímiles de Georgette Vallejo (Obra poéticat completa. Lima: Franciscco Moncloa Editores, 1968). 
- Acabo de verme en París - me dijo- con gente desconocida y a mi lado, una mujer también desconocida. Mejor dicho, estaba muerto $\mathrm{y}$ he visto mi cadáver. Nadie lloraba por mí. La figura de mi madre, en el aire, me alargaba la mano, sonriente. $Y$ añadió:

-Te aseguro que estaba despierto. He tenido la visión en plena vigilia y con caracteres tan animados como si fuera 12 rea, lidad misma. Siento que voy a perder el juicio. Levántate por favor. $^{2}$

Orrego menciona en su artículo que de esa visión premonitoria tuvieron seguramente raíz los dos versos antes citados de "Piedra negra sobre una piedra blanca" y cuatro de "París, Octubre 1936". Y cierra el artículo sin más conjeturas.

La versión siguiente la debemos a Espejo Asturrizaga, amigo y allegado del poeta en Trujillo y Lima:

Durante su permanencia aquí César tuvo una noche una visión que lo llenaría de terror y lo angustiaría por muchos días, siendo el tema de sus conversaciones.

Estaba despierto, decía, cuando de pronto me encontré tendido, inmóvil, con las manos juntas, muerto. Gentes extrañas a quienes yo no había visto nunca rodeaban mi lecho. Destacaban entre éstas una mujer desconocida, cubierta con ropas oscuras $\mathrm{y}$, más allá en la penumbra difusa, mi madre como saliendo del marco de un vacío de sombra, se me acercaba y sonriendo me tendía sus. manos... Estaba en París y la escena transcurría tranquila, serena, $\sin$ llantos. ${ }^{3}$

El lector advertirá que este relato es algo más complejo, pero nada depone o corrige del anterior; difiere sí en convenciones de la prosa y en detalles fúnebres: Vallejo, con las manos juntas, muerto; la mujer con ropas oscuras, y en tal vicisitud, la madre magnificada. Sólo en un motivo el relato de Espejo Asturrizaga parece ajustarse mejor a la real o divulgada muerte de Vallejo: la curiosa "mujer desconocida" viste aquí como de luto. Ha de ser, pues, la esposa del poeta, que sabemos está presente junto al lecho de la clínica donde muere. "Nadie llora-

3 Antenor Orrego, "Una visión premonitoria de César Vallejo", Metatora, III, 16. (México, septienbre-octubre, 1957), pp. 3-4.

3 Juan Espejo Asturrizaga, César Vallejo, itinerario del hombrs. Lima, Editorial Juan Mejía Baca, 1965, pp. 97-98. 
ba", dicen los dos; lo que parece haber sido cierto. "Georgette estaba como átona", atestigua Gonzalo More. ${ }^{4}$

Orrego imprimió en su. nota, naturalmente, lo que era de bulto y con frecuencia conjetura ultranerviosa de Vallejo, vale decir, verse muerto. El hecho es curioso porque premoniza que será en París, cuando el poeta no había salido aún del Perú. Pero Orrego corrobora con poemas que se escribieron en París. El primero, que comienza con los versos ya citados, no corresponde en líneas precisas a su muerte posterior. Dice en él que morirá "con aguacero" cuando en realidad hacía un día radiante; $;^{5}$ que será jueves, cuando fue viernes; que será otoño, cuando fue primavera. Juan Larrea, que ha señalado con aguda precisión las distintas crisis del poeta, menciona su composición en el momento de "abandono y desvalimiento que vivió en Paris desde fines de 1923, y que culminó con su operación de octubre de 1924. Temió Vallejo en esa mala oportunidad el desastre definitivo". "Este poema, que ha sabido distraer a la crítica, fue compuesto apenas cuatro años después de la premonición de Mansiche. Habrá que recurrir entonces a los versos de "París, Octubre 1936" y citados por Orrego:

$$
\begin{aligned}
& \text { mi defunción se va, parte mi cuna } \\
& \text { y rodeada de gente, sola, suelta, } \\
& \text { mi semejanza humana dase vuelta } \\
& \text { y despacha sus sombras una a una. (172) }
\end{aligned}
$$

No se puede prescindir que el poema fue escrito a los tres meses de iniciada la guerra civil española. De ahí que anticipa signos de una realidad premonitoria más firme. Pero Orrego, que ha sabido rescatar parte de ese potencial, no aventura explicarnos sus resonancias. Tal como el problema surge en su conjunto, invita a poner lentes más prácticos en los estímulos psicológicos del sujeto en momento en que contempla su viaje fúnebre, diríamos, arrojado de los "Campos Elíseos", y lo que es significativo, por una causa imprevisible que nadie atina o puede evitar.

\footnotetext{
- Gonzalo More, carta personal al doctor Manuel J. Chávez, París, 24 de mayo de 1938. Este documento se transcribe completo en Aula Vallejo; 5-6-7 (Córdoba, 1967), pp. 393.97.

5 "Era aquella mañana enteramente azul y luminosa, de un azul de cuervo", nos dijo Juan Larrea el día que lo entrevistamos, lo que parece haber sido cierto frente a la mistificación de que entonce llovía tenuemente. Cf. al libro que lleva por título la conferencia de Juan Larrea: César Valleje - Hispano. amêrica en la Cruz de su Razón. Córdoba (Argentina): Editorial Universidad Nacional de Córdoba (Pub. CEFYL), 1957, p. 113.

- Juan Larrea, "Precisiones biográficas", Aula Vallejo, op. cit.. p. 344,
} 
Si se consultan los textos de Orrego y de Espejo Asturrizaga, se verá la importancia que Vallejo atribuye a la circunstancia de que la visión fuera en plena vigilia. En otras palabras, se trata de una certidumbre, no de un sueño. "De todo esto yo soy el único que parte", refiere el primer verso del poema, en el cual una parte viva, consciente del sujeto, ve con asombro en el curso de la misma temporalidad la desesperación de la otra que se ausenta, vaciándose de "sombras una a una" por una especie de oculto castigo.7 A ello se agregan las ausencias del yo acompañadas de otras angustias, que se resumen en los días iniciales de la cuna y los últimos de la defunción. El título "París, Octubre 1936", es explícito del destino que el autor le atribuye al poema y patentiza la situación del sujeto, inerme, rodeado de gente desconocida y por ineluctable contradicción en París, cuando simultáneamente en los primeros dias de octubre la ofensiva rebelde cercaba por cinco rumbos a Madrid. El lector no dejará de intuir las curiosas inversiones personales que el poeta hace de un estado de humanidad en peligro y sin nada providencial para el "único que parte". Asimismo, el verso "de mi número hendido parte a parte", destaca la existencia dividida, precisamente en conexión con aquellos poemas que refieren a números $\mathrm{y}$ madres. ${ }^{8}$ No cabe duda de que, cuando se expresa en Trilce $L$ del guardián que fis. caliza cuánto él come y sueña - - "viejo inminente, pitagórico" que "cuatro veces al dia maneja su candado", y también el XVIII de "las cuatro paredes albicantes/que sin remedio dan al mismo número"- - testimonios de la prisión de Trujillo vienen a colocarse en fila de las circunstancias que acusan aguda crisis en "París, Octubre 1936". El encarcelamiento, tal como confesó haber sido "el momento más grave de mi vida", (228) gravitaria en el cuadro de Mansiche. En ambas situaciones el poeta acude al auxilio materno:

Amorosa llavera de innumerables llaves, si estuvieras aquí, si vieras hasta qué hora son cuatro estas paredes. (95)

7 De otra indole, más bien punitiva de la divinidad, pero semejante en cuanto significa la aniquilación o disolución de todo espiritu de esperanza, lo ilustra Gonzalo de Berceo, refiriéndose a Teófilo: "perdió la sombra, siempre fo desombrado." Milagros de Nuestra Señora, Editorial Clásicos Castellanos, Madrid, 1964, XXIV, p. 170.

8 De Trilce, donde se lee esta correlación de motivos simbólicos, IV: "por to uno y sobre duras áljidas... a no querer dosificar en madre"; XVIII: "las dos largas que tiene esta noche/ algo de madres que ya muertas"; de los cuatro hermanos, entre los que se incluye, dice en el XXIII: "Oh tus cuatro gorgas, asombrosamente/ mal plañidas, madre"; XXVII: "que no le pase nada a mi madre... y siendo ya la 1"; LXXVI: "En nombre de esa pura/ que sabía mirar hasta ser 2". 
Después de Mansiche, en la prisión de Trujillo, el mayor término valorativo resulta la madre; no puede extrañarnos, pues, que asuma la esperanza, portadora además de "llaves", frente al celador que circula con su festón de número y candados. Como estos símbolos nos remiten a las zonas indefinidas de la psicología y el mito, la evocación de "amo. rosa llavera", excede la doméstica entidad de "buena señora de su casa".$^{9}$ Y si expresa "contra ellas seríamos contigo, más dos que nunca", el indicio es de amor filial, capaz de derruir las paredes de la celda, ya que por piedad de ella no pudo el destino entrometer "ni un solo dedo suyo". (133)

Ocurre, sin embargo, que en "París, Octubre 1936", la previsión materna no parece estar presente. Un verso, no obstante, deja ver que "parte mi cuna", por la que sugiere a la madre, sin nombrarla. Su ausencia, o mejor, el hecho de ser el único de los mortales en situación de partida definitiva, ha llegado a la conciencia en forma de total va. cío, como vísperas de muerte, ya que el suceso de Mansiche imponía realmente las sintesis de sus angustias, "cuna" y "defunción", "muerte" y "madre".

Salvo su buen humor, no encuentra ya el poeta los medios de escapar a ese grave prefinal de su vida. A mediados de 1937, mientras la guerra entraba en su etapa crucial, la muerte le parece una condición de horas, y Vallejo deliberadamente fecha sus poemas. El motivo de la madre reaparece como consuelo espiritual, como emergencia simbólica que operaba su cambio a raíz de los sucesos españoles. Los poemas póstumos de España, aparta de mí este cáliz, en efecto, no prescinden de temas épicos y resurrectivos.

"Mas si se ha de sufrir de mito a mito", tal como había definido en Trilce XIX el camino de su vida, Vallejo, previsiblemente, recuerda a su madre con el convencimiento ulterior del que el yo no era más que una discrepante y oscura entidad que sólo podía salvar la piedad colectiva del amor. Vallejo, en tales vicisitudes dolorosas, derivó hacia nuevos valores en el registro de su voz, como exhortar a los "niños, hijos de los guerreros" de ir en pos de la "madre España" en agonía.

9 Es cuanto dictamina Luis Monguió, César Vallejo, Lima: (Editorial Perú Nuevo, 1952), p. 126. Sin embargo, caben otras correspondencias: "Key as an attribute, it pertains to several mythic chatacters, including Hecate", dice J. E. Cirlot, A Dictionary of Symbols, New York: (Edit. Roulledge, 1962), p. 159, puesto que como caso avecinado a la madre de Vallejo, Hécate es madre y porta. dora de las llaves del Hades. Cf. C. G. Jung, Transformaciones y símbolos de la libido, Buenos Aires: (Editorial Paidós, 1952), nota p. 374. Además, las llaves como símbolos rituales de las madres: J. W. Goethe, Fatusto, Barcelona: (Editorial Sopena, 1960), II, pp. 160-64. 
No puede olvidarse, según se descubre en la evolución literaria del poeta, que diez años antes ya figuraban perspectivas amplias del símbolo materno. Justamente, un poema ayudará a comprender que este motivo venía como esperando su término fijado para cristalizar debidamente. André Coyné explica que "Lomo de las Sagradas Escrituras", publicado en 1927, anunciaría las proyecciones proféticas de ssus últimas obras: "de pecho en pecho hasta la madre unánime... Hasta París vengo a ser hijo.... Hombres en verdad te digo que eres el Hijo Eterno". Coyné induce esta fuente: "Chocano, en 1906, al presentar Alma América, lanzaba en nombre del continente la invocación 'Oh, Madre España' que él mismo habría de repetir dos años más tarde en Fiat $L u x x^{\prime} .^{10}$ Desde luego, juicios o expresiones parecidas eran evidentes después de la guerra de 1898 entre Estados Unidos y España. El mismo Darío mucho antes que Chocano escribía "país maternal" en sus prosas de España Contemporánea. Pero Vallejo, por su singularísima manera de ser, no obra por convención. Cuando se le contempla en su verdadero alcance, el lenguaje se libera para cumplir su cometido: de ahí que dice "España" en vez de "Padre, aparta de mí este cáliz", esto es, "madre" tal como por designio obsesivo se apodera con otro propósito de las palabras de Jesús en el Calvario. Junto a la expresión poética, la visión de Mansiche agrega sus acentos igualmente patéticos, de manera que la gravitación de los hechos entran en los dominios de lo escrito. Aquí vale recordar que ocurren tres cosas: lo realmente pre-visto de estar muerto, en París, rodeado de gente desconocida y la mujer de luto; en segundo término, los últimos delirios del poeta; y por fin, el testimonio poético. Los dos ulteriores revelan la visión sublimada de la madre.

De su delirio, previo a la muerte, estas palabras quedan: "Allí... pronto... navajas... me voy a España" ${ }^{11}$ como parecidamente había dicho en Trilce: "Madre voy mañana... a Santiago". (133) La mención de su "Perú del mundo" hubiera sido en ese trance, natural; pero cercana la muerte, el poeta parecía como sometido por la insistencia de un orden alucinatorio que el mismo Vallejo parecía consentir en relación con las circunstancias. Su amor infantil por la madre había tomado

10 André Coyné, Cérar Vallejo y su obra poética, Lima: (Editorial Letras Peruanas, 1958), p. 138.

11 La carta de Gonzalo More al doctor Manuel J. Chávez, ya referida, dice así: "La mujer de Oyarzún sue pasó toda la noche junto a su cabecera cuenta que a las cinco de la mañana llamó a su madre, y media hora antes de morir dija: España, me voy a España". Segín confesión de Juan Latrea en "Memotia de César Vallejo", España Peregrina (abril, 1940), p. 121, dice: "Me estaba llamando a voces - Larrea, Larrea!-, a la vez que pronunciaba el nombre de España, Madre verbal en cuyas manos encomendó su esperanza "definitiva". 
con el tiempo diversas formas: a su novia de Trujillo, a quien llama "nueva madre mia" (24) cuando su madre no había muerto aún; tal vez a París, ciudad en la que se declara "Hijo Eterno" en representación del "Hombre"; y por fin a España. Como corolario, el poeta entraba en coma el 14 de abril de 1938, día en que se quiebra la defensa republicana a lo largo del Ebro. Quedaba así hendido el territorio español, y el azar de las fechas en la vida de Vallejo no agotarían estas vinculaciones que no podían menos que acreditarle - los que seguían de cerca la suerte de España- una muerte simbólica.

Semanas antes, el poeta había escrito España, aparta de mí este cáliz. De esta forma, la premonición en casa de Orrego, cobra el valor oportuno que tienen las convicciones instintivas. Vallejo parece acatar sus imágenes premonitorias como un dictado, comprometido con un hecho ocurrido y que ocurrirá de una vez por todas. Según se lee en sus poemas, presume morirse y se desespera en el más intenso grado. Así parece entenderse también por la carta que compendia tal insinuación y que menciona Orrego. ${ }^{12}$ Hay, efectivamente, el fuerte interés de ser él mismo el protagonista del drama que crea. Se habla con resuclta ironía, previendo que "la bala circula ya en el rango de mi firma". (204) Ha terminado por resignarse y se ve distante de su organismo, de todo un sistema de creencias, casi con gozo vengador: "voy a cerrar mi pila bautismal, esta vidriera". (154) Y más claramente en relación a lo que ocurría en España, con un hecho que sabemos y que señaló el principio del fin de la República: "¡Málaga sin defensa, donde nació mi muerte dando pasos..." (257) Acto continuo éste que había comenzado con el padecido de "París, Octubre 1936".

Por insistente que sea, el verse muerto, sobrevive en su mundo imaginario en forma de una entidad que podría juzgarse paranoica. Si al principio aparece como una regresión de su angustia personal, su "semejanza humana" terminará por ser notoriamente hostil. Colocado ahora junto a los "voluntarios de la vida" que "mueren de universo", le parece oportuno eliminar definitivamente toda individualidad y deman-

12 Los versos citados por Orrego postularían para él y por anticipado los funerales de Vallejo, puesto que el poeta "poseia extrañas facultades premonitorias". Da a entender Orrego en su artículo, que la confirmación de la sospecha de su muerte se la of reció "el mismo Vallejo cuando, en las postrimerías de su vida, desde París me envió las copias de ambas composiciones, con una nota que decía: -iRecuerdas, Antenor, esa visión terrorifica que tuve una noche en tu casa y que me causó tan invencible pavor?" La carta de Vallejo destinada a Orrego, que conocía el suceso de Mansiche, entrañaba esta posibilidad; esa visión pronto será una realidad. Cf. Antenor Orrego, op. citi, p. 5. 
da, por otra disminución más que increíble, la inmolación de su ca: dáver:

Por eso, al referirme a esta agonía

aléjome de mí gritando fuerte:

¡abajo mi cadáver!... Y sollozo. (277)

Se observa justamente que el drama del poeta y el de Vallejo protagonista, están consustanciados. Por analogía con la noche de Mansiche, Vallejo ha entrevisto con credulidad mítica a su madre. Se diría que en dirección a su figura se desplazan una serie de cuadros, una acumulación de visiones. Reaparece Cervantes que dice: "Mi reino es de este mundo, pero también del otro"; Goya, "de hinojos y rezando ante un espejo"; Cajal, "devorado por su pequeño infinito". (249) Una masa lúcida y prometeica: los mendigos que "pelean por España... migaja al cinto"; los proletarios sin quienes "vagarian acéfalos los clavos"; los campesinos que mueren con el gesto digno, "social de su meñique". (250) Sus protagonistas son arquetipos, pesadillas de sus propios y simultáneos abismos: Ramón Collar, con sus dos mensajes de vida y muerte; Ernesto Zúñiga, con el alto trono ideal de su "zapato"; Pedro Rojas, con su ilusión premonitoria: besar después de muerto su catafalco ensangrentado. Bajo este "cielo apocalíptico" (257) de pólvora y humo, imaginó epifanías sociales, míticas y sexuales. ${ }^{1.3}$

La gran mayoría de los poemas que componen España, aparta de mí este cáliz vienen a proyectarse dentro de un orden que se descubire como el único desenlace posible: el rescate de la visión de la madre en el poema que se encabeza con el número catorce de su víspera; en ese poema, Vallejo resume niveles dramáticos y diversos: la madre benigna: "su antebrazo que asen"; la madre severa: "está nuestra maestra con sus férulas, está madre y maestra"; el mundo sin su apoyo: "niños, cómo váis a cesar de crecer"; la madre venerada: "Bajad la voz, que está con su rigor, que es grande"; la madre gestativa de vida y muerte, aderezada según su tratamiento: "y está en su mano, la calavera ha. blando... la calavera, aquella de la vida"; la madre cósmica: "ahora mismo repartiendo la energía entre el reino animal, las florecillas, los cometas y los hombres"; la madre del amor y el sacrificio: "cruz y madera, porque os dio la altura, vértigo y división y suma, niños". (270)

Cuando se vuelve a la comunidad del poema, la primera estrofa, que

13 Málaga, al modo de segunda Eva "huyendo a Egipto" (258), es decir, al desierto perseguida por el dragón del Apocalipsis. 
es preventiva de la exhortación final, contiene la súplica a los niños, seguramente porque ellos ignoran la culpa, los peligros:

Niños del mundo, si cae España - digo, es un decirsi cae

del cielo abajo su antebrazo que asen, en cabestro, dos lágrimas terrestres; niños, qué edad la de las sienes cóncavas! ¡qué temprano en el sol lo que os decía! iqué pronto en vuestro pecho el ruido anciano! iqué viejo vuestro 2 en el cuaderno!14

España no es ya la regia imperial de sus reinos, como ya su madre muerta no lo es de sus huertos. El poeta se asombra de su vejez: "iqué edad la de las sienes cóncavas!" Como procede por alusiones que nacen del fondo de sus recuerdos, la madre se anima de acentos humanos; en los sociales, con el padecimiento colectivo de España. Su agonía, bajo la forma de una caída, se agrava por ser estelar, divina: "si cae - del cielo abajo", hasta el hundimiento: "si cae- España, de la tierra para abajo". Los niños están implícitos en esa caída y también la dignidad de ser hombres:

Si cae - digo, es un decir- si cae

España, de la tierra para abajo, niños, ¡cómo váis a cesar de crecer! ¡cómo va a castigar el año al mes! ¡cómo van a quedarse en diez los dientes, en palote el diptongo, la medalla en llanto!

Los versos que siguen indican algo más grave, tal vez, la esclavitud:

¡Cómo va el corderillo a continuar atado por la pata al gran tintero! ¡Cómo váis a bajar las gradas del alfabeto hasta la letra en que nació la pena!

14 A veces, son admirables las analogías o anticipaciones; en Trilce LXXVl, había dicho si se recuerda: "En nombre de esa pura - que sabía mirar hasta ser $2^{\prime \prime}$. 
Estas palabras parecen referirse al martirio del "cordero", literalmente la naturaleza infantil del pueblo español obligado a padecer la organización inquisitorial de los que persiguen con la pluma en nombre de Dios. Por la misma razón, expresa la importancia que debe asumir la conciencia en la comprensión del sacrificio materno y ruega silencio a los niños: "Bajad la voz, que España está ahora mismo repartiendo la energía entre el reino animal... bajad la voz, el canto de las sílabas, el llanto..." Visiones y oídos infantiles deben responder a los llamados de cólera y también de amor, aun cuando envejecida sobre. lleva un futuro gestativo:

Niños del mundo, está

la madre España con su vientre a cuestas

Como otra médula de sus vísperas, el poeta se incluye en el conjunto evocado, con clara referencia personal: el temor de llegar tarde a la cita final, ya que debía querer asumir junto a los "niños del mundo" el lugar que el mecanismo de Mansiche le venía asignando. (Este anhelo puede corroborarse con aquellas palabras de su delirio: "...me voy a España".) Por la misma virtud, deposita en los niños la fe, que también como en él, pueden alcanzar una suerte de unión inmortal:

\author{
si tardo, \\ si no veis a nadie, si os asustan \\ los lápices sin punta, si la madre \\ España cae - digo, es un decir- \\ salid niños del mundo; id a buscarla!
}

En suma, parece lógico que esta última declaración de "madre España", actuaba en el poeta desde el comienzo, justificado por el apego casi anormal que sintió por la madre a partit de su muerte, y además la visión de Mansiche. Puede así suponerse, ocupado el poeta en traducir emociones premonitorias, que lo que vió en la casa de Orrego no era en realidad su madre personal, sino la madre verbal; la "madre España" bajo los rasgos de la suya propia. Y como tal, no un símbolo de muerte, sino de restauración de la vida.

ARMANDO ZÁRATE

University of Vermont. 